\title{
Engaging college physics students with photonics research
}

\section{Rhys Adams, Lawrence Chen}

Rhys Adams, Lawrence R. Chen, "Engaging college physics students with photonics research," Proc. SPIE 10452, 14th Conference on Education and Training in Optics and Photonics: ETOP 2017, 104522W (16 August 2017); doi: $10.1117 / 12.2257357$

SDIE Event: 14th Conference on Education and Training in Optics and Photonics, ETOP 2017, 2017, Hangzhou, China 


\title{
Engaging college physics students with photonics research
}

\author{
Rhys Adams ${ }^{1}$ and Lawrence R. Chen ${ }^{2}$ \\ ${ }^{1}$ Department of Physics, CEGEP Vanier College \\ 821 Sainte-Croix, Montréal, Canada, H4L 3X9 \\ ${ }^{2}$ Department of Electrical and Computer Engineering, McGill University \\ 3480 University Street, Montréal, Canada, H3A 0E9
}

E-mail: adamsr@vanier.college, lawrence.chen@mcgill.ca

\begin{abstract}
As educators and researchers in the field of photonics, we find what we do to be very exciting, and sharing this passion and excitement to our university students is natural to us. Via outreach programs and college research funding, a new college and university collaboration has broadened our student audience: photonics is brought into the college classroom and research opportunities are provided to college students. Photonics-themed active learning activities are conducted in the college Waves and Modern Physics class, helping students forge relationships between course content and modern communications technologies. Presentations on photonics research are prepared and presented by the professor and past college student-researchers. The students are then given a full tour of the photonics university laboratories. Furthermore, funds are set aside to give college students a unique opportunity to assist the college professor with experiments during a paid summer research internship.
\end{abstract}

Keywords: photonics outreach, active learning, science education

\section{INTRODUCTION}

Promoting scientific and technical research to high school and college students is one of the goals of pre-university education. For some students, it piques their curiosity and motivates them to pursue higher education. For other students, it bridges the gap between what they learn in school and their daily life experiences. In the context of photonics, we can provide fascinating topics of discussion to excite younger science students: photonics plays a fundamental part in their daily consumption of the Internet and has the potential to revolutionize the medical field. By getting young bright minds hooked on photonics, photonics labs will remain populated for years to come and future generations of students will assure research innovation for many years.

The Quebec (provincial) education system is unique to elsewhere in Canada and North America. Students complete their formal high school training after grade 11 . Those wishing to pursue careers requiring university training in science (pure $\&$ applied and health sciences, including medicine), technology, engineering and mathematics (STEM) must first complete a two year pre-university Natural Science program at a college (referred to as CEGEP). These two years are similar to grade 12 and the freshman year in university which is common throughout North American education systems. Quebec students then complete their undergraduate degrees, typically in 3 years for science and $3.5-4$ years for professional programs such as engineering.

The provincial granting agency "Fonds de recherche du Québec - Nature et technologies" (FRQNT) funds three-year research projects led by college professors [1]. The main objectives of these grants include the following: (1) conduct technical research and publish results as university professors do, (2) promote research in the college community, especially to students, and (3) encourage college students to pursue higher education by engaging them in STEM disciplines. We have taken advantage of this program to engage in photonics outreach, stimulate photonics learning in

14th Conference on Education and Training in Optics and Photonics: ETOP 2017, edited by Xu Liu,

Xi-Cheng Zhang, Proc. of SPIE Vol. 10452, 104522W · C 2017 ICO, IEEE, OSA, SPIE

CCC code: $0277-786 X / 17 / \$ 18 \cdot$ doi: $10.1117 / 12.2257357$ 
college-level physics courses, and create exciting research opportunities for high school and college students. For example, students in a college Waves and Modern Physics course engage in active learning activities consisting of reallife and photonic related examples that link to the subject matter discussed in class. Before the semester ends, a summary of the photonics technologies awaits; the students visit university photonics laboratories where research is conducted, and observe experiments that combine the photonic related examples discussed in class. Furthermore, funds are set aside to give some students a unique opportunity to assist the college professor with experiments during a paid summer research internship at the university photonics laboratories. During the following academic year, the student researchers become in-class tutors for the college Waves and Modern Physics course. Among their tasks, they prepare presentations based on their research findings and present their work to the new student cohort.

\section{IN THE COLLEGE WAVES AND MODERN PHYSICS CLASSROOM}

During their two years (4 semesters) in college, natural science students take 12 courses related to mathematics, physics, chemistry, and biology (in addition to general studies and complementary courses). At CEGEP Vanier College, a course on Waves and Modern Physics follows one on Classical Mechanics and precedes one on Electricity and Magnetism.

A typical class size is about 35 students (split in 2 groups for laboratory sessions), with 5 hours of class time per week during the 15 week semester. Class lectures, active learning techniques, and laboratory experiments are used in order for students to understand the physics principles. Topics covered in the course include fundamentals of harmonic motion, mechanical waves, geometric optics, phenomena linked to electromagnetic waves, and modern physics - all of which set the foundation for studies in photonic-related fields. In this context, one of us (RA) brings his photonics experience to class in order to make the physics concepts, such as standing waves and interference, more exciting and to highlight their applications to the real world. In particular, by conducting active learning based activities involving fiber optic telecommunication technologies, students are presented with examples that relate to their day-to-day lives (information and communication technologies, ICT) and augment the subject matter discussed in class. The key components in a fiber based communication link that relate to class content, as presented in figure 1, include:

- $\quad$ Quantization of light, energy levels, resonance and standing waves in lasers.

- Using the unit circle to represent advanced modulation schemes for gigabit per second data transmission.

- Total internal reflection and dispersion in optical fibers for transmitting light signals.

- Interference and grating structures, such as fiber Bragg gratings, for filtering of light signals.

- The photoelectric effect for photodetection of light.

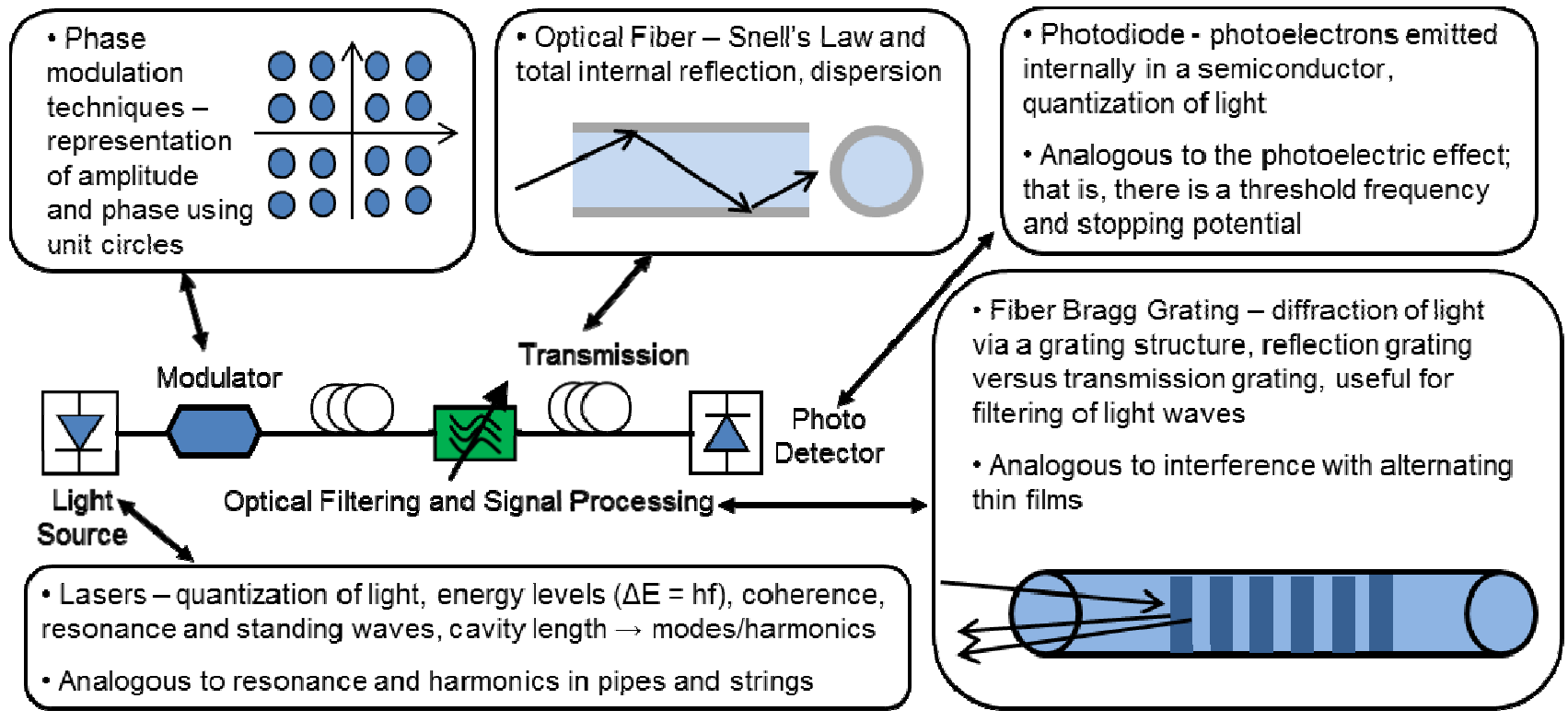

Figure 1: Key components in a fiber based communication link with its relationship to class content. 
Active learning is a practice where students are engaged in classroom activities, as oppose to passively listening to a lecture. In a more traditional classroom, the teacher does most of the talking, restricting opportunities for dialogue between teachers and students. In an active learning setting, the students are at the center of the activity. The teacher leads and scaffolds meaningful activities that facilitate student engagement between them and with the subject matter. There is accumulating evidence that active learning techniques positively impacts the learning of subject matter (including student success as well as understanding fundamental concepts), motivation towards the subject matter, and retention in STEM based programs of study [2-8]. As a result, much of the discussion leading to a better understanding of concepts and linking subject matter to photonics is done in the context of active learning. Such techniques used in the class room include group work, peer instruction [6-8] (including using personal response systems or clickers [7]), problem based learning (PBL), reflective writing exercises [9], computer/ICT based activities [10-14], and learning via informal settings (such as class outings) [15].

For example, in an activity used to review the module on geometric optics and phenomena linked to electromagnetic waves, students are presented with questions dealing with Snell's law, dispersion, interference and diffraction, but all in the context of optical telecommunications, see figure 2. The activity can be implemented in the context of group work, peer instruction and/or as an intro to PBL. First, students are asked to find the maximum launch angle for light to enter the core of the optical fiber that will allow total internal reflection to occur at the core-cladding boundaries. It is simple mathematics, but the exercise generates discussion on how launching light from fiber to fiber is achieved (the students later see fiber coupling during the laboratory visit described below). Students are then prompted to consider the following: (1) If an optical pulse contains many wavelengths of light, what effect does dispersion have on the pulse after it travels kilometres of fiber and how does one compensate this? (2) What happens to light propagating in the core of a fiber, when a series of refractive index changes is introduced in the core, resembling a stack of alternating layers of thin films?

Through this activity, students strengthen their understanding of key concepts relevant to the course (the concept of dispersion extends well beyond rainbows and prisms); they also revisit concepts that previously were difficult to grasp. In particular, the stack of alternating guanine and cytoplasm thin films that gives fish their silvery appearance is not readily understood when they are first introduced to the concept of thin film interference. The fiber Bragg grating is presented as a device that exploits interference and provides the students with an opportunity to solidify their understanding of the phenomena. Furthermore, recent research on integrated Bragg gratings in silicon waveguides, conducted by our students, is then presented as a compare and contrast exercise with respect to traditional fiber Bragg grating.

A consequence from this activity is that it leads to students asking complex questions that are crucial to the implementation of optical telecommunications. For example, attenuation of light is discussed; "does all of the power launched into the fiber arrive to its destination?" Add to that the issue with chromatic dispersion and the student led discussion eventually revolves around signal quality, bit errors, regeneration and amplification, engineering limitations, and cost trade-offs. The questions asked and problems that the students solve in this activity make them probe deeper into the Waves and Modern Physics curriculum. Students not only go beyond the textbook and formulas, they link engineering with physics in a context that is not foreign to them, that is, in this example, to better understand the technology that is behind their daily use of the Internet and ICT. It helps them appreciate what happens from the moment they click download (e.g., for a song) and the moment they can listen to it. Today, students can stream live concerts on their mobile device in high definition while us professors had to wait several hours before a song could be fully downloaded (and it monopolized the household phone landline in the process) - this is shocking to the students! But the physics behind the engineering is fascinating. Physics is more than a textbook filled with equations; physics becomes real.

In two separate computer simulation based activities, students have the opportunity to investigate the physics involved in lasers and with the photoelectric effect. Interactive simulations (PhETs) developed by the University of Colorado (http://phet.colorado.edu) have become an essential tool in the teaching and learning of physics (and for all sciences) [13]. Teachers can incorporate such simulations in an active learning setting, with homework, as part of pre-laboratory assignments, and in some cases, to replace laboratory experiments. In addition to other simulations presented during the semester, the ones for lasers and the photoelectric effect are utilized in the Modern Physics section of the course; each deals with phenomena discussed in class, but furthermore, in the context of photonics, the teacher can motivate the use of lasers and show the parallels between the photoelectric effect to photodetectors for optical telecommunications. 


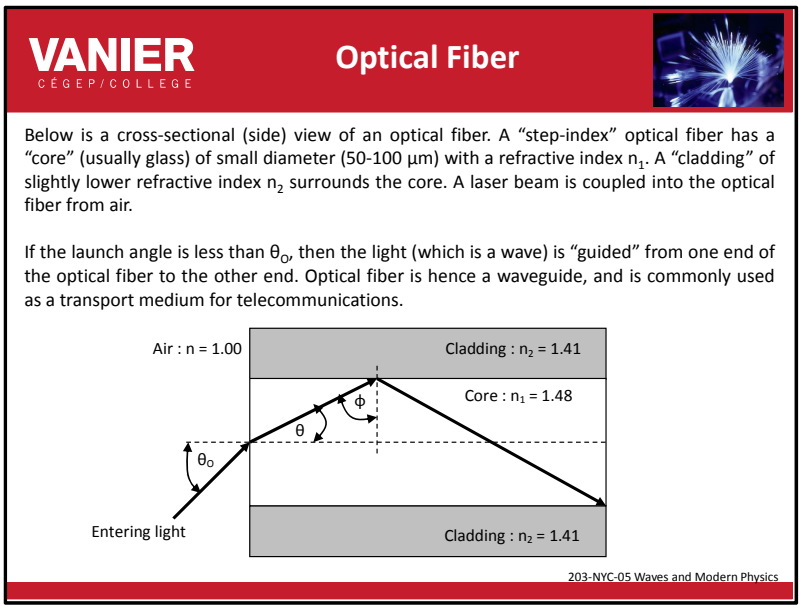

(a)

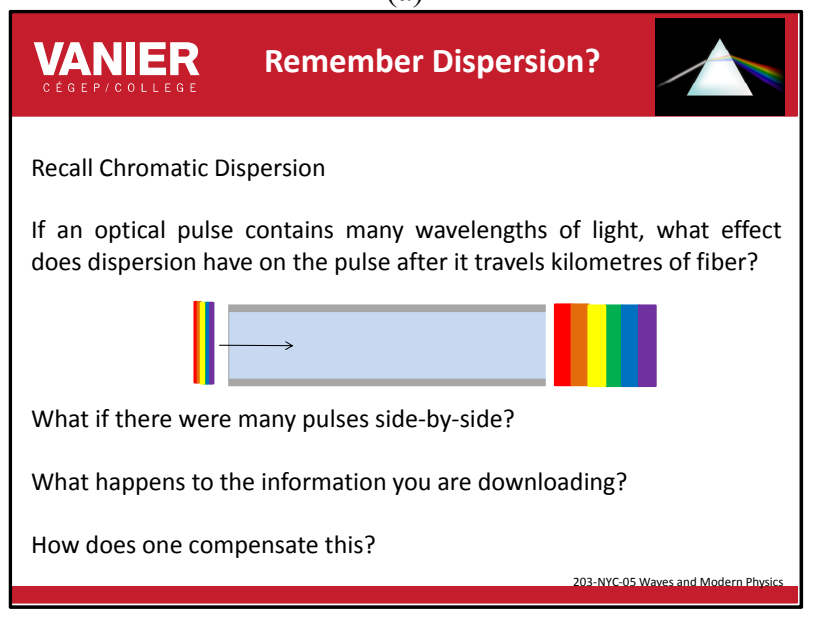

(c)

\begin{tabular}{l} 
Discuss and solve the \\
following questions: \\
(a) Find the phase difference between the reflected rays $\mathrm{R}_{1}$ (between $\mathrm{n}_{1}$ and $\mathrm{n}_{2}$ ) and \\
$\mathrm{R}_{2}$ (between $\mathrm{n}_{2}$ and $\mathrm{n}_{1}$ ). $\mathrm{n}_{1}=1.42$ and $\mathrm{n}_{2}=1.46$. \\
(b) Assuming only the reflected rays $\mathrm{R}_{1}$ and $\mathrm{R}_{2}$, find the thickness of the refractive \\
index $\mathrm{n}_{2}$ such that wavelength $1550 \mathrm{~nm}$ will be most strongly reflected. \\
(c) If we consider ALL reflected rays, the reflected wavelength becomes "sharper" \\
(like when we use a diffraction grating; hence the name "fiber Bragg grating"). Find \\
the thickness of the refractive index $\mathrm{n}_{1}$ such that all reflected rays match in phase for \\
$1550 \mathrm{~nm}$. \\
(d) If a pulse containing many wavelengths of light travels in the fiber Bragg grating, \\
what happens to the other wavelengths (i.e. not $1550 \mathrm{~nm}$ )? \\
203-Nyc-0s waves and Modern Physics \\
\hline
\end{tabular}

(e)

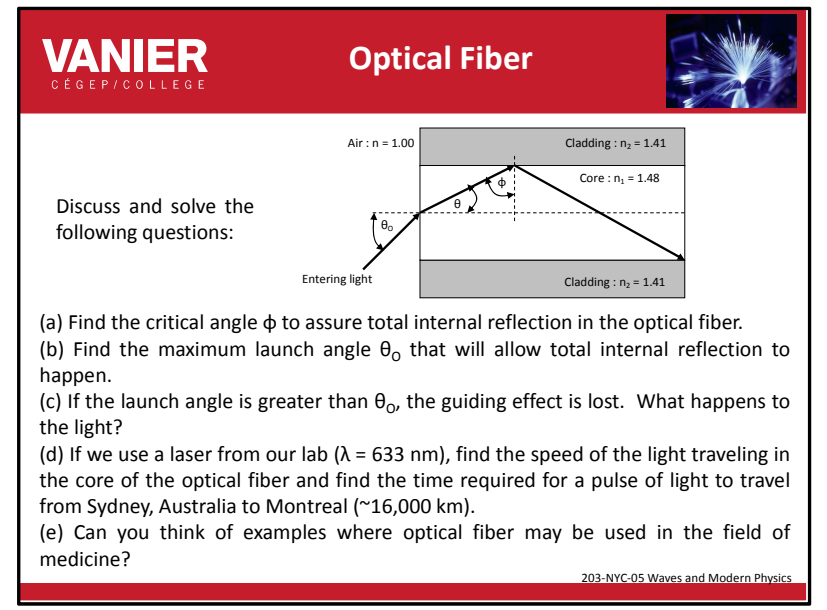

(b)

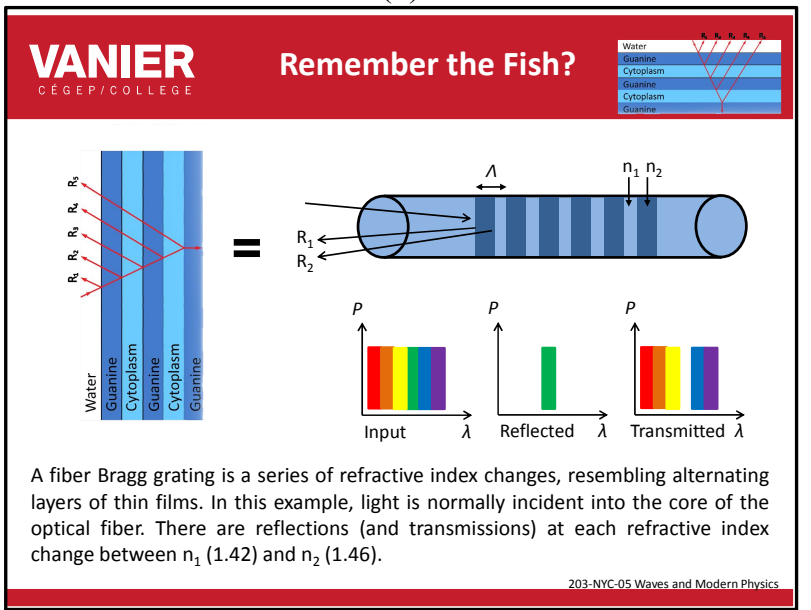

(d)

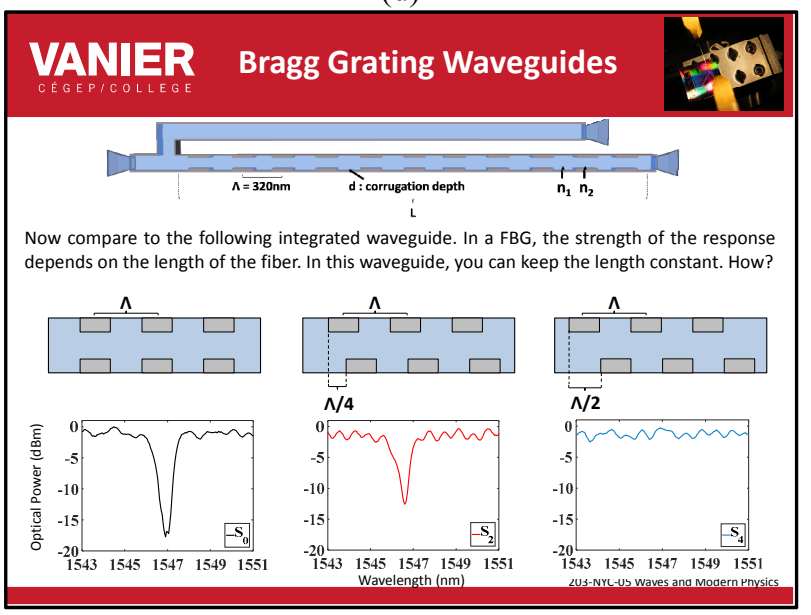

(f)

Figure 2: Series of slides used in an activity to review a module on geometric optics and phenomena linked to electromagnetic waves, but all in the context of optical telecommunications. 


\section{UNIVERSITY PHOTONICS LABORATORIES VISIT}

Late in the semester, the college students are invited to an afternoon visit of undergraduate teaching and graduate research photonics laboratories at McGill University. The Photonics Systems Group (Department of Electrical and Computer Engineering) has world-class, state-of-the-art facilities worth over \$10 million, occupying 4,500 square feet of office and laboratory space; the students are already impressed just taking their first steps in. For many, this is their first time inside university teaching and research laboratories. First, the students are led to an undergraduate laboratory in optics where they see various demonstrations and the type of experiments that undergraduate students complete. Students observe continuous wave light from a laser being modulated, transmitted, and detected. Temporal features of signals are seen on oscilloscopes and their spectral content seen on optical spectrum analyzers (OSAs). Observing OSA traces helps the students with the notion of understanding the frequency representation of signals and builds on their knowledge of harmonics. Observing the complex optical spectrum of a signal helps them understand the notion of the phase of signals and phasors. It also gives a practical perspective to what a complex number is in terms of amplitude and phase. The effects of tuning and filtering of signals are easily observed on an OSA, as is the connecting, severing and splicing of optical fibers. At each step, the professor describes the phenomena, thus emphasizing the subject matter discussed in class.

The students are then given a full tour of the research facilities and have the opportunity to see and discuss the various projects with graduate students. They see both fundamental building blocks seen in class and advanced concepts applied to real-world applications, such as the development of systems that process signals for communications or to enable the detection of a particular molecule for sensing applications. This exchange with the university photonics professor and graduate students also promotes discussions on electrical to optical conversions, optical amplification, optical nonlinear effects, instrumentation, etc. Moreover, it introduces the students to other fields of photonics such as optical computing, spectroscopy, bio-photonics and nano-technology. The cross-disciplinary approach to some photonics research highlights how all the math and science courses taken in college can be interrelated; detecting and fighting cancer cells using photonics is always an enlightening experience for students. Photos taken from the laboratory visits are presented in figure 3.

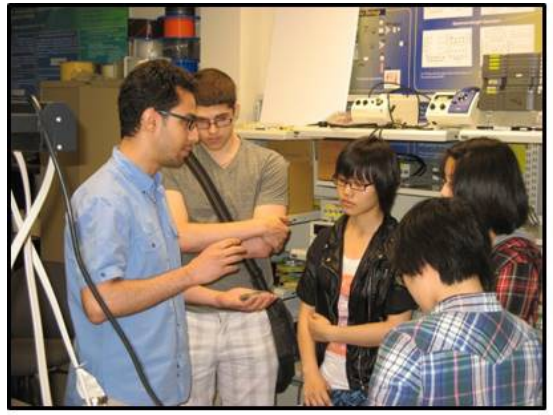

(a)

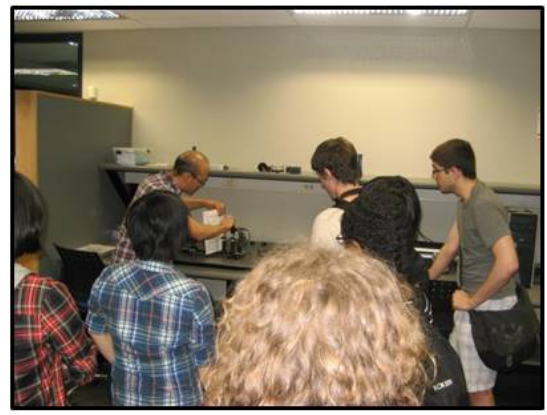

(b)

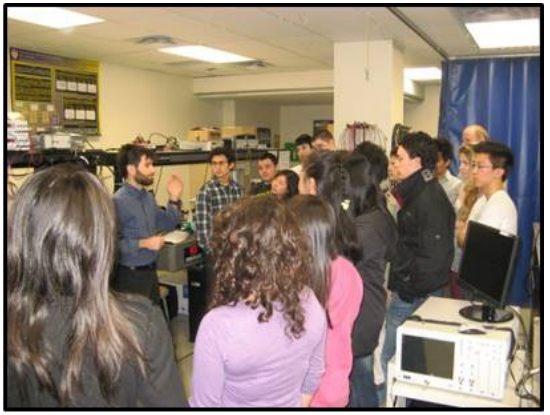

(c)

Figure 3: College students visiting the university undergraduate and graduate photonics laboratories.

\section{PAID SUMMER STUDENT RESEARCH INTERNSHIPS}

Most of the college professor's experimental research is done at McGill University during the summer months, thus providing an opportunity for college students to assist with research during a paid internship. The college professor and students work alongside the university professor, undergraduate, graduate and post-doctoral students. The college students participate in setting up and performing experiments, they assist in the collection, analysis and presentation of the experimental results. They also learn how to use sophisticated test-and-measurement instruments and gain valuable laboratory skills that will benefit them in future college and university courses. As of now, there have been four projects involving college student participation and all projects explored using silicon nanowires (SNW) to build optical signal processing engines. Specifically, we have been exploiting four-wave-mixing (FWM) in SNWs in the implementation of 
microwave photonic filters (MPF) [16, 17], in achieving wavelength conversion and multicasting [18-20] and in RF arbitrary waveform generation (AWG) [21], and we have investigated Bragg grating structures in SNWs [22].

A second year college student participated in the summer 2012 research project, where the objective was to explore different reconfigurable N-tap delay line MPF implementations. In addition to the tasks mentioned above, the student's main role in the project was to prepare excel files to dynamically change the settings of the programmable optical filter, and hence, reconfigure the MPF response. The college student's contributions were valuable and he was a coauthor of a paper presented at the 2013 IEEE Photonics Conference [17]. The student then pursued physics at university, completing an honors bachelor's degree followed by a master's degree.

In summer 2013, we demonstrated error-free wavelength conversion of 16-QAM 28-GBaud signals and 1-to-6 wavelength multicasting of 16-QAM 22-GBaud based on FWM in a SNW. In this project, two first year college students were exposed to advanced modulation schemes that relied on coherent detection receivers, hence highlighting the importance of preserving the phase of signals. The students' contributions were acknowledged in the resulting publications. In addition, at the end of the internship, the college students contributed to the Waves and Modern Physics course content by preparing presentations on modulation schemes and nonlinear processes. They highlighted parts of the research project that linked to the subject matter of the course. Both students presented their work to the following Waves and Modern Physics cohort and prepared a short lecture for the class. In the presentation on modulation schemes, the student compares amplitude shift keying, phase shift keying and quadrature amplitude modulation (QAM) schemes. It is here where the unit circle, a tool used for simple harmonic motion and travelling harmonic waves, is shown to be useful to represent the constellation of QAM signals. The student also presents 16-QAM constellations of different biterror-rates, clearly showing to students which constellations would lead to better performance. The presentation on nonlinear processes begins with a more accurate representation of the index of refraction; then highlighting that in most mediums and in most cases, its value is " $\sim$ n." The student briefly discusses self-phase and cross-phase modulation. For FWM, the process used in our experiments, the student illustrates the relocation of energies from the signal and pump waves and to idler waves, pointing out that the conservation laws (energy and momentum) learned in Mechanics are respected and displaying its application to wavelength conversion and multicasting in the context of routing and distribution of internet data. The college professor has included these presentations in future classroom activities. The students' contribution to pedagogy was highlighted at a local college research conference where the students were present to explain the research project and their pedagogical activities to other researchers [20]. These two students are now studying engineering at university and both were teaching assistants (TAs) for the university professor.

As part of a high school outreach and career program, a high-school student, in addition to a second year college student, joined our research group in summer 2014. As an extension of our past work, we demonstrated RF-AWG based on an Ntap finite impulse response MPF. And as part of the outreach and career program, they were exposed to a university engineering research setting; sitting in on meetings, being part of e-mail exchanges, discussing challenges, solutions, and when possible, explaining the photonics phenomena appropriate to high school math and science knowledge.

Last, a first year college student was involved in the characterization of Bragg grating structures in SNWs during summer 2015. Being very talented as an in-class tutor, the student decided to prepare an extensive presentation describing the research and linking the phenomena to class content in the context of a review session for the following Waves and Modern Physics cohort. He was successful in tying the fundamentals of interference and diffraction to Bragg gratings in fibers and then to SNWs. Furthermore, he then prepared and presented a poster describing both the research results and his addition to the college course curriculum at a local college research conference [22]. The student is currently part of the honors physics program at university.

Photos of all college students involved in summer research internships, along with high school, university undergraduate, graduate and post-doctoral students, are presented in figure 4. 


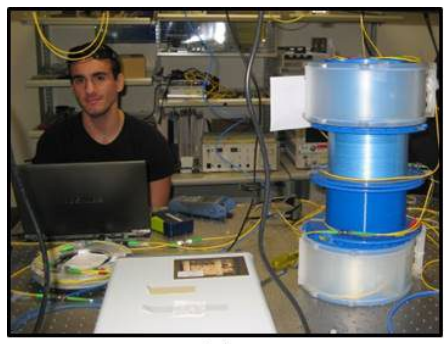

(a)

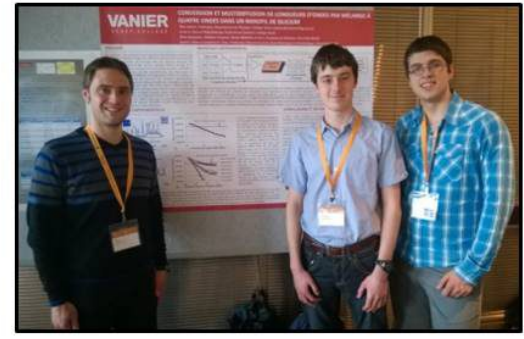

(e)

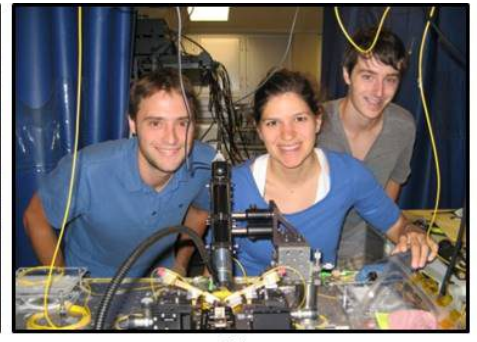

(b)

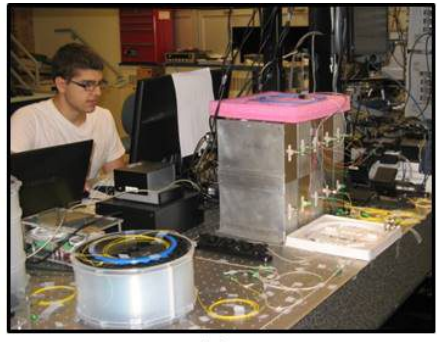

(c)

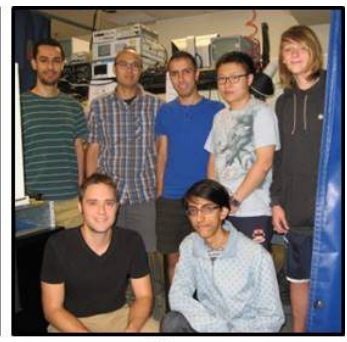

(d)

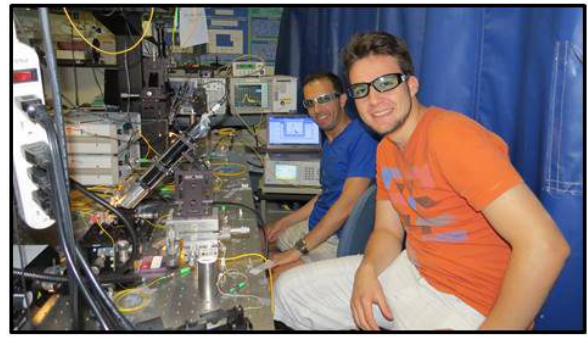

(f)

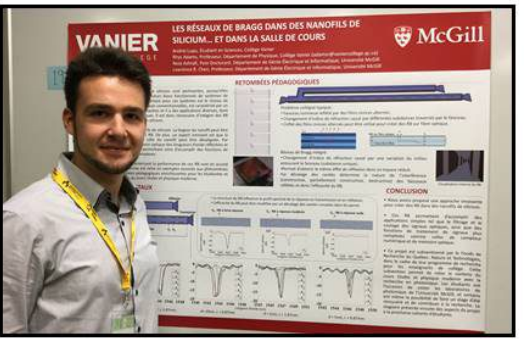

(g)

Figure 4: College students involved in summer research internships; (a) summer 2012, (b-c) summer 2013, (d) summer 2014, (e) Rhys Adams and college students presenting at a local college research conference, spring 2014, (f) summer 2015, (g) college student presenting at a local college research conference, spring 2016.

\section{CONCLUSIONS}

We have presented a unique college-university collaboration and how it has engaged college physics students with photonics. We show how the field of photonics lends itself well with linking college Waves and Modern Physics subject matter to student's day-to-day lives, and how it augments the subject matter discussed in class. Other college professors involved with technical research see this experience as a positive pedagogy tool for students; there is an increasing interest among college professors to pursue their own experiences similar to this one. At the same time, university professors view this experience as a great way to outreach to college students, thus encouraging future broader collaborations between colleges and universities in Quebec. Such collaboration promotes the importance of scientific and technical research to our college students and drives teaching innovation in the class room. Integrating research in and out of the class room can benefit students in all disciplines and in all levels of education.

\section{REFERENCES}

[1] Fonds de recherche du Québec - Nature et technologies: www.frqnt.gouv.qc.ca/accueil (2017).

[2] Hake, R. R., "Interactive-engagement vs traditional methods: A six thousand-student survey of mechanics test data for introductory physics courses," American Journal of Physics, 66, 64-74 (1998).

[3] Freeman, S., Eddy, S. L., McDonough, M., Smith, M. K., Okoroafor, N., Jordt, H., and Wenderoth, M. P., "Active learning increases student performance in science, engineering, and mathematics," Proc. Natl Acad Sci USA, 111 (23), 8410-8415 (2014).

[4] Weiman, C. E., "Large-scale comparison of science teaching methods sends clear message," Proc. Natl Acad Sci USA, 111 (23), 8319-8320 (2014).

[5] Watkins, J., and Mazur, E., "Retaining Students in Science, Technology, Engineering, and Mathematics (STEM) Majors," Journal of College Science Teaching, 42 (5), 36-41 (2013).

[6] Crouch, C. H., and Mazur, E., "Peer Instruction: Ten Years of Experience and Results," American Journal of Physics, 69, 970-977 (2001).

[7] Lasry, N., Mazur, E., and Watkins, J., "Peer instruction: From Harvard to the two-year college," American Journal of Physics, 76, 1066-1069 (2008). 
[8] Zhang, P., Ding, L., and Mazur, E., "Peer Instruction in introductory physics: A method to bring about positive changes in students' attitudes and beliefs," Physical Review Physics Education Research, 13, 010104 (2017).

[9] Kalman, C. S., Aulls, M., Rohar, S., and Godley, J., "Students Perception of Reflective Writing as a Tool for Exploring an Introductory Textbook,” Journal of College Science Teaching, 37, 74-81 (2008).

[10] Adams, R., Lenton, K., and Dedic, H., "ICT (\& TLC) improves student motivation in physics courses," Proc. Canadian Association of Physicists Annual Conference, poster 92 (2013).

[11] Lenton, K., and Adams, R., "Student-Generated Videos in the Physics Classroom," Canadian Association of Physicists - Physics in Canada Journal: Special Issue on Physics Education in Canada, 70 (2), 117-119 (2014).

[12] Miller, K., Zyto, S., Karger, D., Yoo, J., Mazur, E., "Analysis of student engagement in an online annotation system in the context of a flipped introductory physics class," Physical Review Physics Education Research, 12, 020143 (2016).

[13] Perkins, K., Adams, W., Dubson, M., Finkelstein, N. D., Reid, S., Wieman, K. and LeMaster, R., "PhET: Interactive Simulations for Teaching and Learning Physics," Physics Teacher, 44, 18-26 (2006).

[14] Petosa, A., Adams, R., Mulcair, G., Brotto, G. and Manley, L., "Leveraging Web-based Technologies to Enhance Collaborative Learning: SMART AMP," Workshop presented at Supporting Active Learning and Technological Innovation in Studies of Education (SALTISE) Annual Conference, Montréal, Québec (2016).

[15] Bartley, J. E., Mayhew, L. M., and Finkelstein, N. D., "Promoting Children's Understanding And Interest In Science Through Informal Science Education,” Proc. Physics Education Research Conference, AIP Press, 1179, 93-96 (2009).

[16] Chen, L. R., Li, J., Spasojevic, M., and Adams, R., "Nanowires and sidewall Bragg gratings in silicon as enabling technologies for microwave photonic filters," Optics Express, 21, 19624-19633 (2013).

[17] Adams, R., Li, J., Sarac, Z., Berardo, D., and Chen, L. R., "Comparing Nonlinear Fiber and a Silicon Nanophotonic Waveguide for Implementing a Microwave Photonic Filter," Proc. IEEE Photonics Conference, paper WC1.2 (2013).

[18] Adams, R., Spasojevic, M., Chagnon, M., Malekiha, M., Li, J., Plant, D. V., and Chen, L. R., "Wavelength conversion of 28 GBaud 16-QAM signals based on four-wave mixing in a silicon nanowire," Optics Express, 22, 40834090 (2014).

[19] Chagnon, M, Spasojevic, M., Adams, R., Li, J., Plant, D. V., and Chen, L. R., "Wavelength Multicasting at 22 GBaud 16-QAM in a Silicon Nanowire using Four-Wave Mixing," IEEE Photonics Technology Letters, 27, 860-863 (2015).

[20] Adams, R., Crea, L. A., Roberge, P., Spasojevic, M., Chagnon, M., Malekiha, M., Li, J., Plant, D. V., and Chen, L. R., "Conversion et multidiffusion de longueurs d'ondes par mélange à quatre ondes dans un nanofil de silicium," Proc. Association francophone pour le savoir (2014).

[21] Adams, R., Ashrafi, R., Wang, J., Dizaji, M. R., and Chen, L. R., "RF-Arbitrary Waveform Generation Based on Microwave Photonic Filtering,” IEEE Photonics Journal, 6, 5501208 (2014).

[22] Lupu, A., Adams, R., Ashrafi, R., and Chen, L. R., "Les réseaux de Bragg dans des nanofils de silicium... et dans la salle de cours," Proc. Association francophone pour le savoir (2016). 